\title{
Isolation and Identification of an Antioxidant Product from the Reaction Mixture of Dehydroascorbic Acid with Tryptophan
}

\author{
Mitsuo Namiki, Tateki Hayashi and Akira Shigeta \\ Department of Food Science and Technology, Nagoya University, \\ Chikusa-ku, Nagoya 464, Japan
}

Received October 22, 1981

\begin{abstract}
Several substances with antioxidant activity were isolated from the mixture of dehydroascorbic acid and tryptophan when reacted together in ethanol. One of the main antioxidant products was obtained in crystalline form from an $n$-butanol extract of the reaction mixture by means of Sephadex column chromatography followed by HPLC with a reversed phase column. ${ }^{1} \mathrm{H}$ - and ${ }^{13} \mathrm{C}$ NMR of the product and its acetate showed its structure as a condensate of dehydroascorbic acid and tryptophan with each single molecule involving a C-spiro structure. By a POV test the activity of this substance was about two-thirds of that of BHA on a molar basis, and the activity of the reaction mixture is greatly attributable to this substance.
\end{abstract}

In the preceding paper it was reported that the equimolar reaction mixture of dehydroascorbic acid (DHA) with Trp showed an antioxidant activity comparable to BHA by the POV method. ${ }^{1)}$ The fraction of such activity was located on a TLC plate, and was found to contain an indole moiety in the structure. The present paper deals with the isolation and identification of one of the principal products from the $n$-butanol extract of the reaction mixture.

\section{Isolation of the antioxidant product $\mathbf{1}$}

DHA and Trp were reacted in ethanol as described in the preceding paper, ${ }^{1)}$ and the reaction mixture was extracted with $n$-butanol after the ethanol had been removed. The antioxidant activity tests and TLC showed that the products in question were transferred to the solvent and most of the residual materials and other products remained in the aqueous layer. $n$-Butanol was the most suitable solvent among those tested. No activity was transferred to ether, benzene, chloroform and ethyl acetate. Column chromatography of the extracts on Sephadex LH-60 using 99\% ethanol gave varicolored bands and was accordingly fractionated. The eluate was separated into eight fractions according to their UV absorbance (Fig. 1) and three of them showed antioxidant activity by the POV method. Two of these fractions (Nos. 7 and 8) suffered from persistent tailing by brown substances, and therefore, one other (No. 4) was subjected to further purification.

The concentrate of the fraction No. 4 was subjected to reversed phase HPLC with Bondpack $\mathrm{C}_{18}$ Porasil $\mathrm{B}$, was separated into three fractions $4 \mathrm{a}, 4 \mathrm{~b}$ and $4 \mathrm{c}$ and the latter two of these were active in the POV test (Fig. 2). The main fraction $4 b$ was only lightly yellow while $4 \mathrm{c}$ was brown colored and seemed to be a contaminant of the brown fraction in the preceding chromatography. Then, the former one was freeze-dried and its methanol solution was treated in a short charcoal column and concentrated to give colorless needles (1).

Acetylation of 1 with acetic anhydridepyridine followed by purification, using HPLC with silica gel, provided colorless crystalline acetate, 2 .

\section{Structures of $\mathbf{1}$ and $\mathbf{2}$}

Elemental analysis of $\mathbf{1}$ was consistent with 


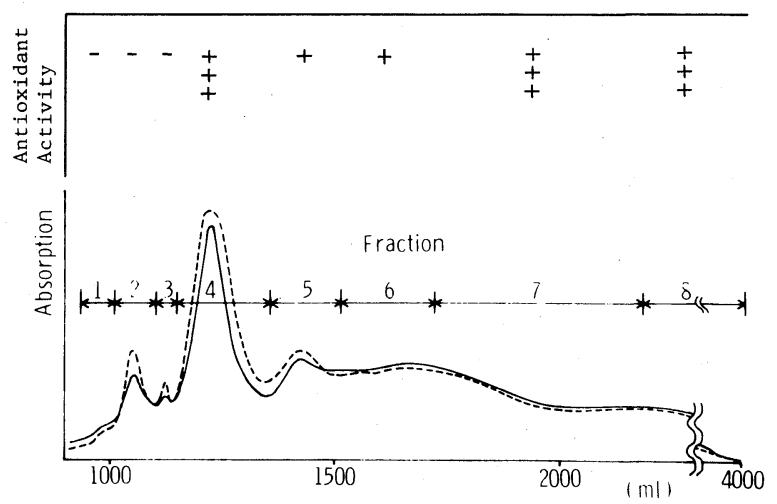

FIG. 1. Gel Chromatogram of Reaction Mixture of Dehydroascorbic Acid with Tryptophan and Antioxidant Activity of Each Fraction.

Column, Sephadex LH-60; solvent, 99\% ethanol; _-, $260 \mathrm{~nm} ;------, 280 \mathrm{~nm}$.

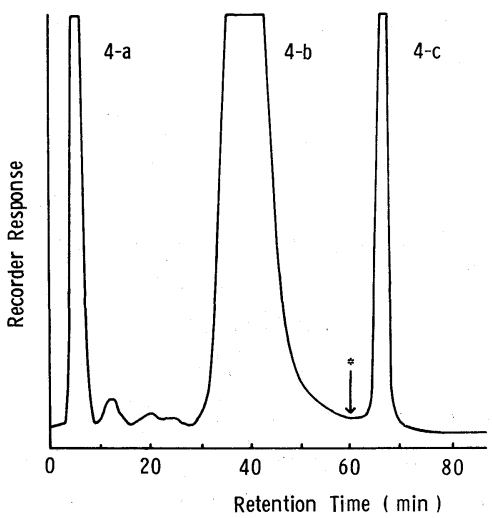

FIG. 2. HPLC of Fraction 4 in the Chromatogram Shown in Fig. 1.

Column, Bondapak $\mathrm{C}_{18}$ Porasil-B; solvent, watermethanol-acetic acid (400:200:3).

* Changed to methanol.

the formula $\mathrm{C}_{17} \mathrm{H}_{18} \mathrm{~N}_{2} \mathrm{O}_{8}$. MS of 1 did not provide any clear spectrum indicating a molecular ion peak, but acetate 2 gave $\mathrm{M}^{+} 426$. The high resolution MS of $\mathbf{2}$ indicated a formula of $\mathrm{C}_{21} \mathrm{H}_{18} \mathrm{~N}_{2} \mathrm{O}_{8}$. These formulae suggested that 1 involves two molecules of water of crystallization, that is $\mathrm{C}_{17} \mathrm{H}_{14} \mathrm{~N}_{2} \mathrm{O}_{6} \cdot 2\left(\mathrm{H}_{2} \mathrm{O}\right)$, and 2 is its diacetate, $\mathrm{C}_{17} \mathrm{H}_{12} \mathrm{~N}_{2} \dot{\mathrm{O}}_{6} \cdot 2\left(\mathrm{CH}_{3} \mathrm{CO}\right)$. Accordingly, 1 was assumed to be a condensate of DHA and Trp with one molecule each by elimination of two molecules of water.

The results of ${ }^{1} \mathrm{H}$ - and ${ }^{13} \mathrm{C}-\mathrm{NMR}$ of $\mathbf{1}$ and $\mathbf{2}$ are summarized in Table I. Two methylene protons at $\delta 2.76$ and $\delta 3.20$ had a large ger- minal coupling constant $(J=15.3 \mathrm{~Hz})$ and, moreover, each of these was coupled with the signal at $\delta 3.96$. These suggest that they belong to the side chain of $\operatorname{Trp}-\mathrm{C}(\mathrm{H})_{2}-\mathrm{CH}-$ constituting a certain ring structure. ${ }^{2)} \mathrm{A}$ proton of the doublet of doublet at $\delta 3.96$ was shifted by 1.4 ppm to the lower field in the acetate 2 , suggesting that the side chain nitrogen has at least one proton which will easily give an acetyl derivative.

The presence of the indole ring, inferred from the characteristic UV spectrum around $280 \mathrm{~nm},{ }^{1)}$ was also supported by the multiplet signals indicating aromatic protons, but their number was four, one less than expected for the Trp moiety. This was also supported by the ${ }^{13} \mathrm{C}-\mathrm{NMR}$ of $\mathbf{1}$, that showed only four aromatic carbons with an attached proton. It seemed probable that the proton corresponding to that lacking is the one on the $\mathrm{C}-2$ position of Trp, because it is usually reactive and would be substituted readily by another group.

In the ${ }^{1} \mathrm{H}-\mathrm{NMR}$ of $\mathbf{1}$, two doublet of doublets at $\delta 4.20$ and $\delta 4.53$ showed an extensive geminal coupling $(J=13.3 \mathrm{~Hz})$ and each of them was also coupled with a triplet at $\delta 4.57$. These signals and, additionally, a singlet at $\delta 4.83$ seemed to correspond to the protons at C-4, C-5 and C-6 in the cyclic DHA, respectively. ${ }^{3)}$ The ${ }^{13} \mathrm{C}-\mathrm{NMR}$ peaks of 1 at 73.7 , 88.7 and $77.2 \mathrm{ppm}$ also corresponded well to 
TABle I. ${ }^{1} \mathrm{H}$ - AND ${ }^{13} \mathrm{C}-\mathrm{NMR}$ Data of 1 AND 2

\begin{tabular}{|c|c|c|c|c|}
\hline \multirow{2}{*}{$\begin{array}{c}\text { No. } \\
\text { of } \\
\text { position }\end{array}$} & \multicolumn{2}{|c|}{$\delta_{\mathrm{H}}(\mathrm{Hz})$} & \multicolumn{2}{|c|}{$\delta_{\mathrm{C}}(\mathrm{OFR})$} \\
\hline & 1 & 2 & 1 & 2 \\
\hline $1\left(2^{\prime}\right)$ & & & $63.7(\mathrm{~s})$ & $59.3(\mathrm{~s})$ \\
\hline 3 & $3.96(1 \mathrm{H}, \mathrm{dd}, 4.7,11.4)$ & $5.37(1 \mathrm{H}, \mathrm{dd}, 2.0,6.0)$ & 53. $2(\mathrm{~d})$ & $55.1(\mathrm{~d})$ \\
\hline \multirow[t]{2}{*}{4} & $2.76(1 \mathrm{H}, \mathrm{dd}, 11.4,15.3)$ & $3.18(1 \mathrm{H}, \mathrm{dd}, 2.0,16.3)$ & $26.8(\mathrm{t})$ & $25.8(\mathrm{t})$ \\
\hline & $3.20(1 \mathrm{H}, \mathrm{dd}, 4.7,15.3)$ & $3.54(1 \mathrm{H}, \mathrm{dd}, 6.0,16.3)$ & & \\
\hline 57 & & & $112.2(\mathrm{~d})$ & $112.4(\mathrm{~d})$ \\
\hline 6 & $69 \sim 76(4 \mathrm{H}-\mathrm{m})$ & $6.9 \sim 7.6(4 \mathrm{H}, \mathrm{m})$ & $113.5(\mathrm{~s})$ & $114.7(\mathrm{~s})$ \\
\hline 7 & $0.3 \sim 1.0(411, \mathrm{II})$ & $0.307 .0(411,111)$ & 118.7 (d) & $119.0(\mathrm{~d})$ \\
\hline 8 & & & $119.6(d)$ & $120.1(\mathrm{~d})$ \\
\hline 10 & & & $122.9(\mathrm{~d})$ & $123.5(\mathrm{~d})$ \\
\hline 11 & & & $127.1(\mathrm{~s})$ & $125.2(\mathrm{~s})$ \\
\hline 12 & & & $127.2(\mathrm{~s})$ & $126.0(\mathrm{~s})$ \\
\hline 13 & & & $137.6(\mathrm{~s})$ & $137.8(\mathrm{~s})$ \\
\hline 14 & & & $172.9(\mathrm{~s})$ & $169.4(\mathrm{~s})$ \\
\hline $1^{\prime}$ & & & $174.3(\mathrm{~s})$ & $170.3(\mathrm{~s})$ \\
\hline $3^{\prime}$ & & & $110.1(\mathrm{~s})$ & $110.1(\mathrm{~s})$ \\
\hline $4^{\prime}$ & $4.83(1 \mathrm{H}, \mathrm{s})$ & $5.16(1 \mathrm{H}, \mathrm{s})$ & $73.7(\mathrm{~d})$ & $74.3(\mathrm{~d})$ \\
\hline $5^{\prime}$ & $4.57(1 \mathrm{H}, \mathrm{t}, 7.0)$ & $5.41(1 \mathrm{H}, \mathrm{dd}, 3.0,5.8)$ & $88.7(\mathrm{~d})$ & 85.1 (d) \\
\hline \multirow[t]{2}{*}{$6^{\prime}$} & $4.20(1 \mathrm{H}, \mathrm{dd}, 7.0,13.3)$ & $4.18(1 \mathrm{H}, \mathrm{dd}, 3.0,10.5)$ & $77.2(t)$ & $76.6(\mathrm{t})$ \\
\hline & $4.53(1 \mathrm{H}, \mathrm{dd}, 7.0,13.3)$ & $4.59(1 \mathrm{H}, \mathrm{dd}, 5.8,10.5)$ & & \\
\hline 2-Ac-Me & & $2.32(3 \mathrm{H}, \mathrm{s})$ & & $20.6(q)$ \\
\hline $5^{\prime}-\mathrm{Ac}-\mathrm{Me}$ & & $2.84(3 \mathrm{H}, \mathrm{s})$ & & \} $20.9(q)$ \\
\hline 2-Ac-CO & & & & $167.3(\mathrm{~s})$ \\
\hline $5^{\prime}-\mathrm{Ac}-\mathrm{CO}$ & & & & $\int 168.9(\mathrm{~s})$ \\
\hline
\end{tabular}

Solvent, acetone- $d_{6}$.

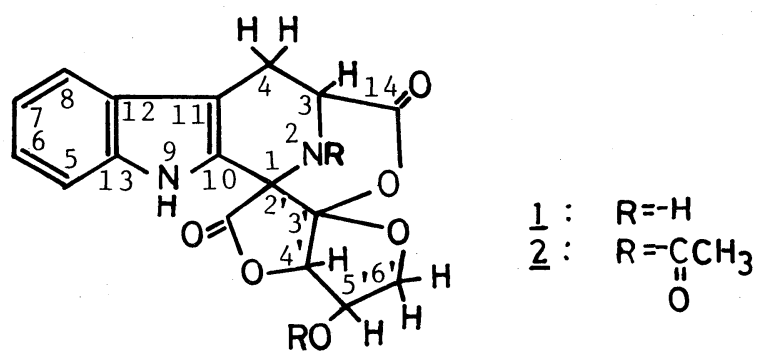

those of C-4, C-5 and C- 6 of the cyclic DHA. ${ }^{3)}$ These suggest that the side chain of the ascorbic acid moiety of $\mathbf{1}$ has a ring structure formed by dehydration of C-6 OH with C-3 $\mathrm{OH}$. The proton signal at 84.57 was shifted to a lower field in the acetyl derivative 2 by 0.84 ppm indicating that the $\mathrm{OH}$ at $\mathrm{C}-5$ is free and would be easily acetylated. A signal at 110.1 ppm in the ${ }^{13} \mathrm{C}$-NMR spectrum of $\mathbf{1}$ seemed to be due to $\mathrm{C}-3$ of the ascorbic acid moiety from the corresponding signal of DHA. However, no signal corresponding to $\mathrm{C}-2$ of DHA was found in the spectrum of $\mathbf{1}$. We assumed the unidentified signal appearing at $63.7 \mathrm{ppm}$ was attributable to C-2 in the ascorbic acid moiety; a large shift to a higher field is probably explained by postulating a conformation at $\mathrm{C}$ 2 , such as a spiro-ring structure.

Many studies have been done on the reaction of Trp with carbonyl compounds. Triose reductone is known to react with Trp under the acidic condition to yield an amino reductone type condensation product, ${ }^{4)}$ but such a compound is apparently of a different type from 1 in every aspect, including antioxidant activity. Interesting examples are the 
reactions of Trp with ninhydrin and other carbonyl compounds to give 1,2,3,4tetrahydro- $\beta$-carboline derivatives, ${ }^{5,6)}$ because the above-mentioned NMR data of product 1 and $\mathbf{2}$ are reasonably explained by postulating a tetrahydro- $\beta$-carboline structure.

A singlet signal at 172.9 or $174.3 \mathrm{ppm}$ of ${ }^{13} \mathrm{C}-\mathrm{NMR}$ of 1 was assigned to the carboxyl carbon of the Trp moiety but, on the other hand, ${ }^{1} \mathrm{H}$-NMR indicated absence of a free carboxyl group. This is probably explained by the presence of a lactone ring involving C-3 of the ascorbic acid moiety. We have no direct evidence for the lactone ring, but no other conceivable structure seems to fit the data; for example, a ring formation involving indole nitrogen was shown to be improbable on the grounds of the configurational study using a Dreiding model. Thus the structure of $\mathbf{1}$ is proposed as shown in Table I below.

\section{Antioxidant activity of $\mathbf{1}$}

The antioxidant activity of $\mathbf{1}$ was determined at different concentrations in comparison with BHA and $\alpha$-tocopherol by the POV method. The results shown in Fig. 3 indicate that the product 1 increased the induction period almost linearly with doses, which is a feature markedly different from the cases of BHA and tocopherol, where the curves showed maxima at relatively lower concentrations. Direct comparison of the antioxidant activity of $\mathbf{1}$ to those of the known antioxidants is therefore not possible, but it may be said that it is about two-thirds of that BHA on a molar basis.

The results of the study of the synergistic effect of various known synergists on $\mathbf{1}$ are shown in Fig. 4. As has been observed with the original reaction mixture, ${ }^{1)}$ the product 1 exhibited a marked synergistic effect with $\alpha$-tocopherol but no detectable synergism with ascorbic acid and others.

\section{Quantitative investigation on the formation of 1}

Examination of the HPLC conditions made it possible to determine the product 1 quanti-

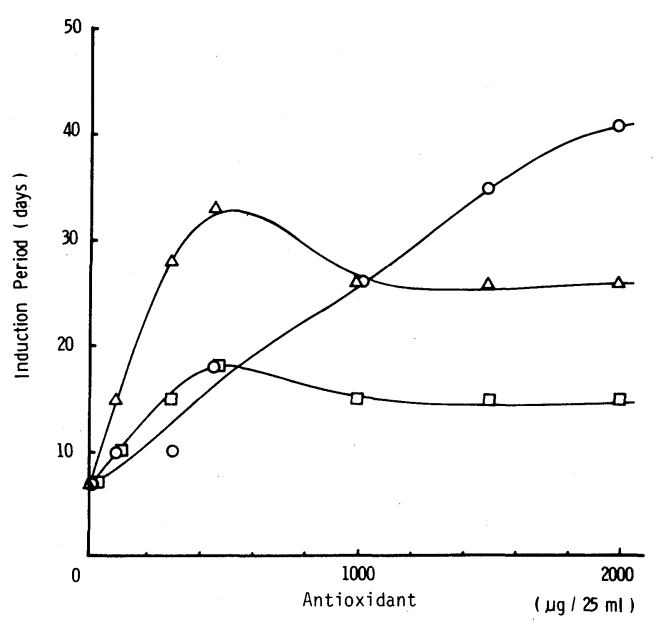

FIg. 3. Antioxidant Activities of the Product 1, BHA and $\alpha$-Tocopherol at Different Concentrations.

$-\mathrm{O}-$, product $1 ;-\triangle-, \mathrm{BHA} ;-\square-, \alpha$-tocopherol. Each sample was added to $25 \mathrm{ml}$ of the testing oil solution.

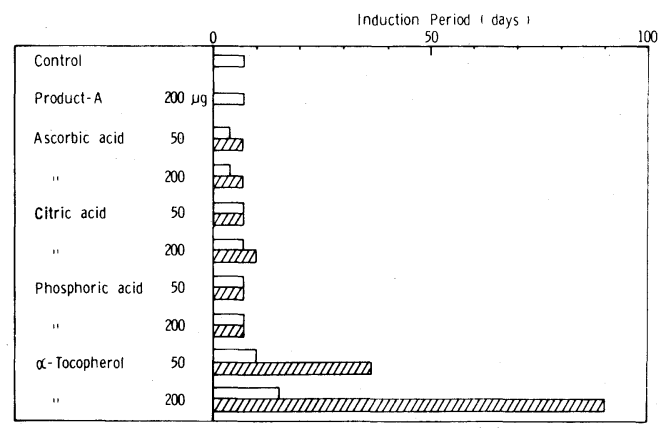

FIG. 4. Synergistic Effects of the Product 1 with Various Compounds.

, without product $1 ; \square 7 \nearrow$, with product 1 . Each sample was added to $25 \mathrm{ml}$ of the testing oil solution.

tatively and directly in the reaction mixture. The procedure was essentially the same as those mentioned above in the isolation of 1 except for the substitution of Bondapak C-18 Porasil by a Merck RP-18 column. Typical chromatograms are shown in Fig. 5. The results with purified $\mathbf{1}$ indicate a linear correlation between the amount of $\mathbf{1}$ and the height of peak a and as low as $1 \mu \mathrm{g}$ of 1 in the reaction mxiture could be determined. The formation of 1 during the reaction of DHA with Trp in ethanol was pursued, along with the progress of the browning, the formation of the red pigment and others. As shown in Fig. 


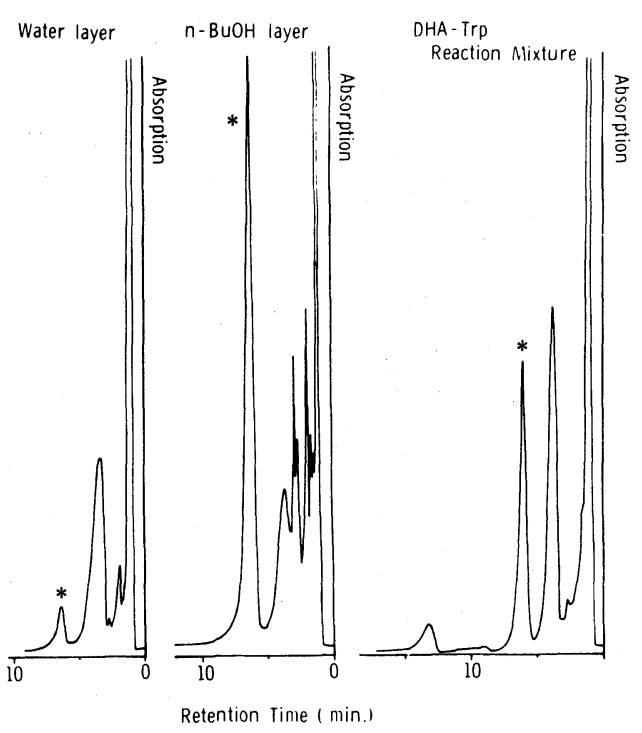

FIG. 5. HPLC for Quantitative Measurement of the Product $\mathbf{1}$ in the Reaction Mixture, $n$-Butanol Extracted Layer and Residual Water Layer.

* Peak of product 1. column, Merck RP-18; solvent, water-methanol-acetic acid (400:200:3); detector, at $254 \mathrm{~nm}$.

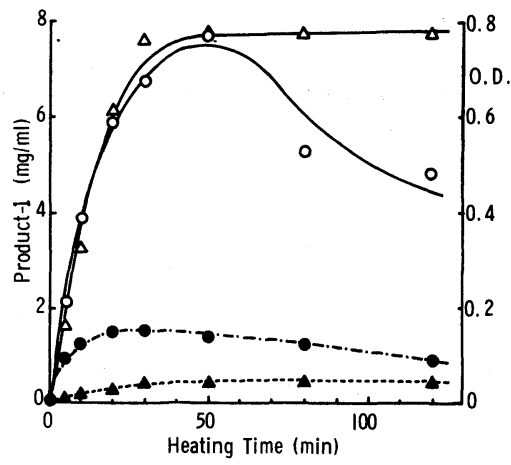

FIG. 6. Changes in Amounts of the Product 1, Red Pigment and Browning Product during Reaction of Dehydroascorbic Acid with Tryptophan.

- - -, product 1, -.-- --.-, red pigment (at $510 \mathrm{~nm}$ ); $-\triangle-$, browning (at $420 \mathrm{~nm}$ ); -- $\Delta-\cdots$, radical precursor (at $630 \mathrm{~nm}$ ).

6, the product 1 formed rapidly at an early stage of the reaction parallel with the browning, showed a maximum at about $50 \mathrm{~min}$ and then decreased gradually with prolonged heating. Yield of 1 at the maximum point was estimated to be about $20 \%$ for the materials. The strecker degradation products as the red pigment and the radical precursor ${ }^{7)}$ were also formed almost in parallel with the formation of the product 1 .

\section{CONCLUSION}

We were able to isolate a new compound as one of the main antioxidant principles of the reaction mixture of DHA with Trp, and proposed its chemical structure as shown in Table I. This is likely to be the first case of the isolation and identification of antioxidant products formed by the amino-carbonyl reactions of food constituents. Further studies, however, are needed to examine the possibility of practical utilization in food preservation and to clarify the nature of the other main antioxidant principles present in the reaction mixture. In connection to the former, a preliminary experiment on the mutagenicity of 1 by Ames bacterial tests ${ }^{8)}$ with TA 98 and TA 100 strains showed that the mutagenicity of 1 is negligible. It seems also of interest to investigate other biochemical activities of 1 , especially in connection with the recent findings on the inhibitory effects of antioxidants on cell aging $^{9)}$ and mutagen activity. ${ }^{10)}$

\section{EXPERIMENTAL}

DHA was prepared as its dimer by oxidation of Lascorbic acid with $p$-benzoquinone. ${ }^{11)}$ Trp and other reagents were of guaranteed grade. The reaction conditions and antioxidant test using the POV method were essentially the same as reported previously. ${ }^{1)}$

UV spectra were recorded with a Hitachi 200-10 spectrometer. ${ }^{1} \mathrm{H}$ - and ${ }^{13} \mathrm{C}-\mathrm{NMR}$ were measured with a JNMMH-100 and a JNM-FX-100, respectively. IR spectra were measured with a JASCO A-3. MS and high resolution MS were obtained on a JNM-D-100 and JMS01SG, respectively. HPLC was performed using a Waters 6000 A equipped with RI detector R401.

1. Isolation of 1. A solution of DHA $(0.1 \mathrm{M})$ and Trp $(0.1 \mathrm{M})$ in $95 \%$ ethanol $(50 \mathrm{ml})$ was refluxed for $50 \mathrm{~min}$ to give a dark brown reaction mixture. Filtration to remove a slight amount of residual Trp followed by concentration in vacuo gave $7.3 \mathrm{~g}$ of brown product, which was dissolved in $50 \mathrm{ml}$ of $n$-butanol and washed five times with $100 \mathrm{ml}$ distilled water to remove the water-soluble materials and products as residual materials and ascorbic acid, and then 
concentrated in vacuo to yield $4.1 \mathrm{~g}$ of brown product. A portion of the product $(1.0 \mathrm{~g})$ was submitted to a Sephadex LH-60 column $(4.12 \times 45 \mathrm{~cm})$ and eluted with $99 \%$ ethanol $(100 \mathrm{ml} / \mathrm{hr})$ monitering the absorbance at $260 \mathrm{~nm}$ (Fig. 1). The eluates corresponding to the fraction 4 were concentrated in vacuo. As a pretreatment of the following HPLC, the concentrate was dissolved with a small amount of methanol and chromatographed on a short column $(1.2 \times 8.1 \mathrm{~cm})$ with Bondapack $\mathrm{C}_{18}$ Porasil-B and watermethanol-acetic acid $(400: 200: 3)$ as the solvent to remove the brown products and other adsorbable products, followed by freeze drying. The preparative HPLC $(1 \times 150$ $\mathrm{cm}, 9 \mathrm{ml} / \mathrm{hr}$ ) was carried out with the same packing and solvent system, and the coromatogram monitored with $\mathrm{UV}$ at $254 \mathrm{~nm}$ is shown in Fig. 2. The eluates corresponding to the fraction 4-b were collected and freeze-dried to give yellow powder. The product was further purified on a short charcoal (Norit) column $(2 \times 1.2 \mathrm{~cm})$ to remove the yellow impurity with methanol as solvent, and subsequent evaporation gave a colorless crystalline product, $195 \mathrm{mg}$ (yield $11 \%$ ). Recrystallization from ethyl acetate gave white needles, decomp. at $172 \sim 176^{\circ} \mathrm{C}$. UV $\lambda_{\max }(\mathrm{EtOH})$ 226, 276, 284, $293 \mathrm{~nm}$. IR (KBr) 1786, $1720 \mathrm{~cm}^{-1}\left(v_{\mathrm{C}=\mathrm{o}}\right)$, $3300 \mathrm{~cm}^{-1}\left(v_{\mathrm{N}-\mathrm{H} \text { or } \mathrm{O}-\mathrm{H}}\right)$. Elemental analysis, Anal. Found: C, $52.99, \mathrm{H}, 4.75, \mathrm{~N}, 7.05 \%$. Calcd. for $\mathrm{C}_{17} \mathrm{H}_{18} \mathrm{~N}_{2} \mathrm{O}_{8}$ : C, 53.97, H, 4.80, N, 7.41\%. ${ }^{1} \mathrm{H}$ - and ${ }^{13} \mathrm{C}-\mathrm{NMR}$ data are shown in Table I. $\mathrm{p} K=4.8$.

2. Acetate of 1 . A solution of $1(90 \mathrm{mg})$ in $5 \mathrm{ml}$ pyridine was added to $3 \mathrm{ml}$ of acetic anhydride under cooling with ice-water and left overnight at room temperature. The reaction mixture was poured into $50 \mathrm{ml}$ of ethyl acetate and washed four times with $20 \mathrm{ml}$ protions of $0.5 \mathrm{~N} \mathrm{HCl}$ and then several times with $20 \mathrm{ml}$ portions of water. The solvent layer was dried over $\mathrm{Na}_{2} \mathrm{SO}_{4}$ and evaporated. The residue was further purified by HPLC (Licrosorb SI-60, with EtOAc- $n$-hexane $(1: 2), 2 \mathrm{ml} / \mathrm{min})$ and concentrated to give a white crystalline product $(72 \mathrm{mg})$. UV $\lambda_{\max } 219$, $275,282,291 \mathrm{~nm}$. IR, $1675 \sim 1800 \mathrm{~cm}^{-1}\left(v_{\mathrm{C}=0}\right)$. MS $m / z$ $(\%) 426\left(\mathrm{M}^{+}, 52\right), 356$ (77), 213 (73), 196 (100), 168 (75). High resolution $\mathrm{MS}, \mathrm{M}^{+}, 426.1074$. Calcd. for $\mathrm{C}_{21} \mathrm{H}_{18} \mathrm{~N}_{2} \mathrm{O}_{8}, 426.1063$.

\section{REFERENCES}

1) M. Namiki, A. Shigeta and T. Hayashi, Agric. Biol. Chem., 46, 1199 (1982).

2) ${ }^{1} \mathrm{H}-\mathrm{NMR}$ Data of Tryptophan, "NMR Spectra Catalog," Compiled by N. S. Bhacca et al. of the Instrument Division of Varian Associates, 1963, p. 582.

3) J. Hvoslef and B. Pederson, Acta Chem. Scand., B33, 503 (1979).

4) K. Shinohara, Y. K. Tseng, F. Uchino and H. Omura, Nippon Nôgeikagaku Kaishi, 49, 463 (1975).

5) A. Heesing, R. Müller-Matthesrus and H. Rose, Lieb. Ann. Chem., 735, 72 (1970).

6) D. G. Harvey, E. J. Miller and W. Robson, J. Chem. Soc., 1941, 153.

7) M. Yano, T. Hayashi and M. Namiki, Agric. Biol. Chem., 42, 2239 (1978).

8) B. N. Ames, J. McCann and E. Yamazaki, Mutation Res., 31, 347 (1975).

9) L. A. Witting, "Free Radicals in Biology," ed. by W. A. Pryor, Academic Press, New York, 1980.

10) R. J. Shamberger, C. L. Corlett, K. D. Beaman and B. L. Kasten, Mutation Res., 66, 349 (1979).

11) M. Yano, T. Hayashi and M. Namiki, J. Agric. Food Chem., 24, 815 (1976). 